\title{
Trefftz method in solving Fourier-Kirchhoff equation for two-phase flow boiling in a vertical rectangular minichannel
}

\author{
Sylwia Hożejowska ${ }^{1, *}$, Magdalena Piasecka $^{2}$, Artur Piasecki ${ }^{3}$ \\ ${ }^{1}$ Faculty of Management and Computer Modelling \\ ${ }^{2}$ Faculty of Mechatronics and Mechanical Engineering \\ ${ }^{3}$ contractor of the project from the Polish National Science Centre (No. DEC-2013/09/B/ST8/02825) \\ Kielce University of Technology, Al. 1000-lecia P.P. 7, 25-314 Kielce, Poland
}

\begin{abstract}
This paper presents the results of investigations into flow boiling heat transfer in an asymmetrically heated vertical minichannel of $1.7 \mathrm{~mm}$ depth. The heated element for FC-72 flowing in the minichannel was an alloy plate $0.45 \mathrm{~mm}$ thick, microstructured on one side, in direct contact with the flowing fluid. The computational part of the study contains approximate steady state solutions of the heat transfer problems described by Poisson's equation and the energy equation for the heated plate and the fluid, respectively. For both equations, the boundary conditions were specified on the basis of experimental data. Temperature of the outer plate surface, measured by infrared thermography, and heat losses to ambient air were included in the calculations. For the energy equation we assumed parabolic profile of fluid velocity and the equality of temperatures and heat fluxes at the interface between the heated surface and the fluid. The void fraction was taken from a single-phase flow model. Two-dimensional temperature distributions were obtained by the Trefftz method and, due to the Robin condition at the interface between them, it was possible to calculate the heat transfer coefficient. Its values were compared to those obtained by other correlations known from literature.
\end{abstract}

\section{Introduction}

The importance of flow boiling heat transfer applications to mini spaces of different geometries has recently increased considerably. New generations of cooling systems have been designed and their huge heat dissipation capacity has greatly increased heat removal rate per unit heat transfer area. Effective cooling schemes using flow boiling heat transfer in mini- and microchannels to maintain device temperature are being developed. The application of microstructured heated surfaces in minichannels attracts attention due to theoretical enhancement of their potential for transferring large heat fluxes. Consequently, this issue has become a promising aim of the study.

A review of literature relating to flow boiling heat transfer in minichannels with microstructured surfaces, smooth and enhanced, was presented in [1-3]. The literature fails to offer any generalized conclusions for predicting heat transfer in small channels. Focusing research on microstructured surface of heat exchangers with minichannels seems interesting because these surfaces provide a potential for further heat transfer enhancement.

In $[2,3,5]$ the authors proposed one- and twodimensional heat transfer model for a minichannel with an enhanced heated surface. The two-dimensional temperature distribution on the heated plate was determined by the Finite Element Method combined with Trefftz functions as shape functions (FEMT). In this paper, two sets of Trefftz functions were used to calculate 2D temperature distributions both for the heated plate and for the working fluid, FC-72. The numerical results obtained for the heat transfer coefficient were compared with the correlations reported in the literature.

\section{Experimental test}

The study was conducted for FC-72 boiling in a rectangular, vertical and asymmetrically heated minichannel with a depth (height) of $1.7 \mathrm{~mm}$, a width of $18 \mathrm{~mm}$ and a length of $180 \mathrm{~mm}$, figure 1. Perfluorocompound FC-72 is $3 \mathrm{M}$ Fluorinert ${ }^{\mathrm{TM}}$ Electronic Liquid, thermally and chemically stable, compatible with sensitive materials, nonflammable, practically nontoxic and leaves essentially no residue upon evaporation. The experimental setup was presented in [1-6]. The heated element for FC-72 flowing in the minichannel (1) was the plate made of Haynes-230 alloy with thickness of $0.45 \mathrm{~mm}$ (2) which was microstructured on one side in direct contact with the fluid flowing in the channel. Cavities (8) in the plate surface were made by electromachining. An image of the section with cavities

* Corresponding author: ztpsf@tu.kielce.pl 
is also shown in figure 1 . The depth of the cavity craters is usually below $1 \div 2 \mu \mathrm{m}[1,2,6]$. It was possible to observe the plate surface through a glass pane (4) using a digital SLR camera (10). The camera allowed conducting two-phase flow visualizations on the microstructured plate side. K-type thermocouples (7) and pressure transducers were installed at the inlet and outlet of the minichannel. The temperature of the smooth side of the heated plate was measured by FLIR E60 infrared camera (9) in the central axially symmetric part of the minichannel. The plate was coated with a black paint (3) with a known emissivity [2,5]. Thermal accuracy of the infrared camera was $\pm 1{ }^{\circ} \mathrm{C}$ or $\pm 1 \% \pm 1{ }^{\circ} \mathrm{C}$ or $\pm 1 \%$ within the temperature range of $0 \div 120^{\circ} \mathrm{C}$ (temperature used in the experiment was within this range).

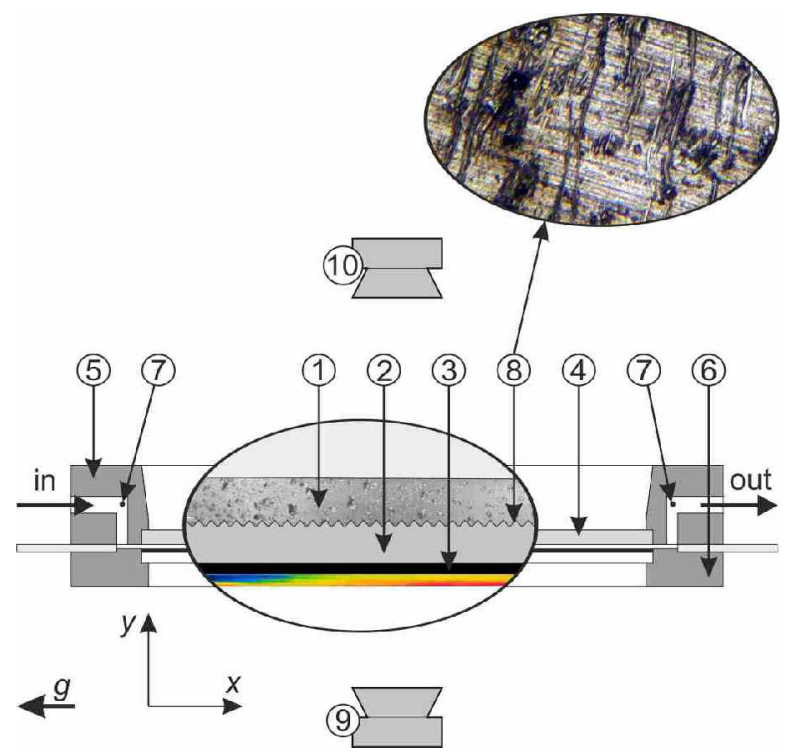

Fig. 1. The schematic diagram of a measurement module with a minichannel, 1-minichannel, 2-heated plate, 3-black paint, 4-glass panel, 5-channel body, 6-front cover, 7-thermocouple, 8-microstructured surface with cavities, image of the fragment with cavities, 9-infrared camera, 10-SLR camera.

\section{Mathematical model and calculations}

We assumed that physical phenomena on the side edges of the module did not affect the thermodynamic parameters in the segment of concern. From here our considerations focused on the central part of the measurement module for which only two dimensions were taken into account: dimension $x$ along the flow, and $y$ relating to the thickness of the module composed of the heated plate and the minichannel. The steady state heat transfer process in the heated surface was described by two-dimensional Poisson's equation with an adequate system of boundary conditions, as shown in [2,5]. It was assumed that the flow of FC-72 was laminar and stationary with a constant mass flux density and that its flow velocity in the minichannel has one component parallel to the heated plate (the other component takes the value of zero). The temperature of liquid at the interface with the heated surface depends on the temperature of the heated plate $\left(T_{H}\right)$ and the temperature of saturation at a given pressure $\left(T_{s a t}\right)$ in the way presented in [7]. In addition, the liquid temperature at the minichannel inlet $\left(T_{l, \text { in }}\right)$ and outlet $\left(T_{l, \text { out }}\right)$ is known. The two-phase mixture that formed in the minichannel contained a gaseous phase and the liquid phase in proportions dependent on void fraction $\varphi(x)$. For the two-phase flow it is assumed that the entire heat flux from the heated plate is transferred to the liquid phase in proportions dependent on the void fraction

$$
\lambda_{l} \frac{\partial T_{l}}{\partial y}=\lambda_{H}(1-\varphi(x)) \frac{\partial T_{H}}{\partial y}
$$

where $\lambda$ denotes thermal conductivity. The void fraction $\varphi(x)$ was determined from the Spedding correlation [8]

$$
\varphi(x)=\left(1+2.22\left(\frac{1-X(x)}{X(x)}\right)^{0.65}\left(\frac{\rho_{v}}{\rho_{l}}\right)^{0.65}\right)^{-1}
$$

Local thermodynamic vapour quality $X(x)$ was determined from the formula [9]

$$
X(x)=\frac{\left(q_{F}-q_{\text {loss }}\right)\left(x-x_{\text {sat }}\right)}{W G h_{l v}}
$$

where the heat flux generated by the heated plate $q_{F}$ was reduced by the heat flux transferred to the environment $q_{\text {loss }}$, [2]. In (3) $W$ is the heated plate width, $G$ - mass flux, $h_{l v}$ - heat of vaporization, $\rho$ - density, $x-$ the distance from the heated section starting point, subscripts: $l$ - is intended for liquid phase and $v$ - for vapour phase. The location where boiling starts $x_{\text {sat }}$ was given by the formula

$$
x_{\text {sat }}=\frac{G A c_{p}\left(T_{\text {sat }}-T_{l, \text { in }}\right)}{\left(q_{F}-q_{\text {loss }}\right) L}
$$

where $L$ is the minichannel length, $A$ - field, $G$ - mass flux, $c_{p}-$ specific heat. Where the heated plate temperature and the liquid temperature distributions and gradient $\lambda_{H} \partial T_{H} / \partial y$ were known, the heat transfer coefficient $\alpha(x)$ at the plate-liquid interface could be determined using the condition

$$
\alpha(x)_{\exp }=\frac{-\lambda_{H} \frac{\partial T_{H}}{\partial y}\left(x, \delta_{H}\right)}{T_{H}\left(x, \delta_{H}\right)-T_{l, a v e}(x)}
$$

where $\delta_{H}$ is the plate thickness. The reference temperature $T_{l, a v e}$ was taken as the mean liquid temperature in the interval $\left\langle 0,0.5 \delta_{M}\right\rangle$ where $\delta_{M}$ is the minichannel depth, [9]. The unknown approximations of the heated plate and liquid temperatures were determined using the Trefftz method [10]. First, the approximation of the plate partition temperature $T_{H}$ was found by solving the inverse heat conduction problem in the procedure described in [11]. These approximations were calculated using the Trefftz functions for Laplace's equation. Then, the approximation of the liquid 
temperature $T_{l}$ was determined by solving another inverse problem.

The Trefftz functions for energy equation with the parabolic liquid velocity were used to determine liquid temperature $[9,11]$. The solutions obtained with Trefftz method fulfil exactly the governing differential equation are continuous functions and has a differentiable form.

\section{Results}

Figure 2 shows the heat transfer coefficient, calculated from (5), which depends on the distance along the minichannel length and on the increasing heat flux supplied to the heated plate. Moreover, figure 3 shows the heat transfer coefficient versus the vapour quality calculated according to equation (3), obtained for four distances from the channel inlet: $0.045 \mathrm{~m}, 0.09 \mathrm{~m}$, $0.135 \mathrm{~m}$ and $0.153 \mathrm{~m}$.

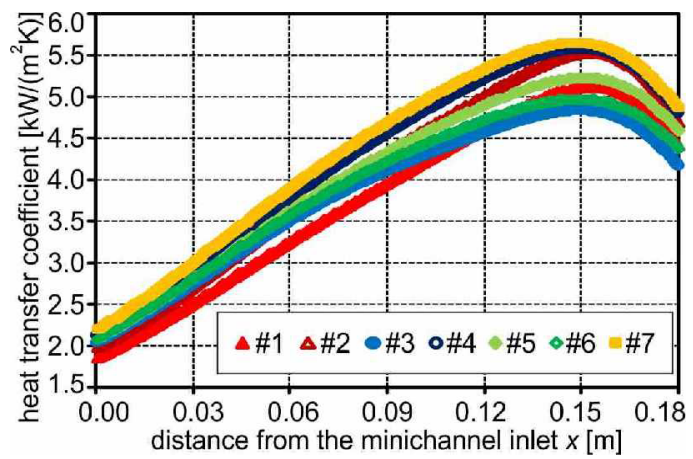

Fig. 2. Heat transfer coefficient versus the distance along the length of the minichannel, experimental parameters (average): mass flux $420 \mathrm{~kg} /\left(\mathrm{m}^{2} \mathrm{~s}\right)$, inlet pressure $110 \mathrm{kPa}$, inlet liquid subcooling $40 \mathrm{~K}$, heat flux densities: \#1) $q_{\mathrm{w}}=58 \mathrm{~kW} / \mathrm{m}^{2}$, \#2) $q_{\mathrm{w}}=66 \mathrm{~kW} / \mathrm{m}^{2}$, \#3) $q_{\mathrm{w}}=76 \mathrm{~kW} / \mathrm{m}^{2}$, \#4) $q_{\mathrm{w}}=86 \mathrm{~kW} / \mathrm{m}^{2}$, \#5) $\left.q_{\mathrm{w}}=90 \mathrm{~kW} / \mathrm{m}^{2}, \# 6\right) q_{\mathrm{w}}=94 \mathrm{~kW} / \mathrm{m}^{2}$, \#7) $q_{\mathrm{w}}=102 \mathrm{~kW} / \mathrm{m}^{2}$.

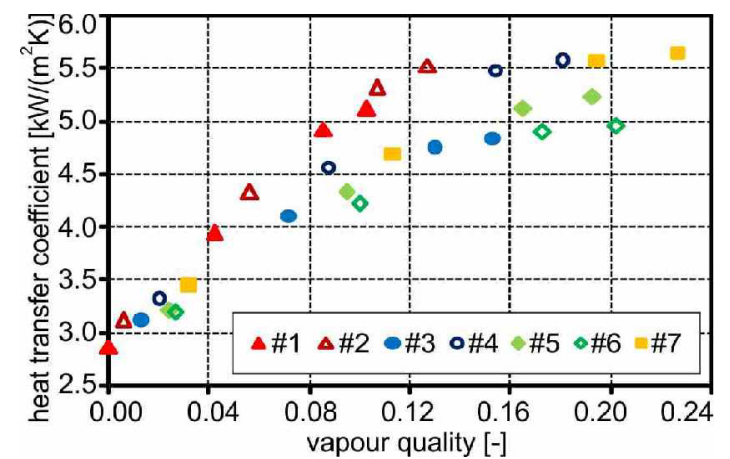

Fig. 3. Heat transfer coefficient versus vapour quality, experimental parameters as for figure 2 , data for $0.045 \mathrm{~m}, 0.09 \mathrm{~m}, 0.135 \mathrm{~m}$ and $0.153 \mathrm{~m}$ distances from the minichannel inlet.

The experimental data show a monotonic increase in the values of local heat transfer coefficient with the distance from the minichannel inlet up to the distance of $0.15 \mathrm{~m}$. At that point a drop in the coefficient value is observed.

\section{Comparative analysis with other correlations}

To compare the data obtained, five correlations known from literature were selected: the Lazarek and Black correlation [12], the Liu and Winterton correlation [13], the Warrier et al. correlation [14], the Sun and Mishima correlation [15] and the Bertsch et al. correlation [16], presented in [1]. All the selected correlations were dedicated to flow boiling heat transfer in channels.

In the correlations presented below, dimensionless numbers should be computed according to the equations known from literature; $d_{h}$ is a hydraulic diameter, the other quantities were defined earlier in this paper.

\subsection{Lazarek and Black correlation}

Lazarek and Black [12] proposed the following correlation:

$$
\alpha=\left(30 R e_{l}^{0.857} B o^{0.714}\right)\left(\lambda_{l} / d_{h}\right)
$$

where $R e$ - Reynolds number, Bo - Boiling number.

\subsection{Liu and Winterton correlation}

Liu and Winterton [13] presented the correlation in the following form:

$$
\alpha_{t h}=\sqrt{\left(F \alpha_{l}\right)^{2}+\left(S \alpha_{n b}\right)^{2}}
$$

where

$$
\begin{aligned}
& F=\left[1+X \cdot \operatorname{Pr}_{l} \cdot\left(\rho_{l} / \rho_{v}-1\right)\right]^{0.35} \\
& S=\left(1+0.055 \cdot F^{0.1} \cdot \operatorname{Re}_{l}^{0.16}\right)^{-1}
\end{aligned}
$$

$\alpha_{l}$ - should be calculated from the Dittus-Boelter correlation

$$
\alpha_{l}=\left(0.023 \operatorname{Re}_{l}^{0.8} \operatorname{Pr}_{l}^{0.4}\right)\left(\lambda_{l} / d_{h}\right)
$$

$\alpha_{n b}$ - should be determined according to the Cooper correlation [17].

\subsection{Warrier et al. correlation}

The Warrier et al. correlation has the following form [14]:

$$
\alpha=\left[1+6 B o^{1 / 16}-5.3(1-855 B o) X^{0.65}\right] \alpha_{l}
$$

where Bo - Boiling number, $X$ - vapour quality, $\alpha_{l}$ - should be calculated from the Dittus-Boelter correlation - eq. (10). 


\subsection{Sun and Mishima correlation}

The Sun and Mishima correlation [15] was based on the Lazarek and Black correlation

$$
\alpha_{t h}=\frac{6 R e_{l}^{1.05} B o^{0.54}}{W e_{l}^{0.191}\left(\rho_{l} / \rho_{v}\right)^{0.142}} \frac{\lambda_{l}}{d_{h}}
$$

where We - Weber number, other quantities such as density and similarity numbers as listed above.

\subsection{Bertsch et al. correlation}

Bertsch et al. [16] proposed the following dependence:

$$
\alpha_{t h}=S \alpha_{n b}+F \alpha_{S P}
$$

where

$$
\begin{gathered}
S=1-X \\
\alpha_{S P}=\alpha_{v}+(1-X) \alpha_{l} \\
F=1+80\left(X^{2}-X^{6}\right) \exp (-0.6 C o)
\end{gathered}
$$

- for turbulent flow $\alpha_{l}$ and $\alpha_{v}$ should be calculated from the Dittus-Boelter correlation, eq. (10),

- for laminar flow:

$$
\alpha_{t h_{-} v / l}=\frac{\lambda_{v / l}}{d_{h}}\left[3.66+\frac{0.0668 \operatorname{Re}_{v / l} \operatorname{Pr}_{v / l} d_{h} / L}{1+0.04\left(\operatorname{Re}_{v / l} \operatorname{Pr}_{v / l} d_{h} / L\right)^{2 / 3}}\right]
$$

In eq. (17) dimensionless numbers should be computed according to the equations known from the literature.

Figure 4 compares the experimental heat transfer coefficient $\alpha_{\text {exp }}$ to the results of calculations based on theoretical correlations $\alpha_{t h}$ (discussed above). The data shown in figure 3 were chosen as experimental heat transfer coefficients used for the comparison.

The best agreement was achieved by using the Liu and Winterton correlation within the margin of error of $\pm 50 \%$. Good compliance was also found when the Bertsch et al. correlation was used.

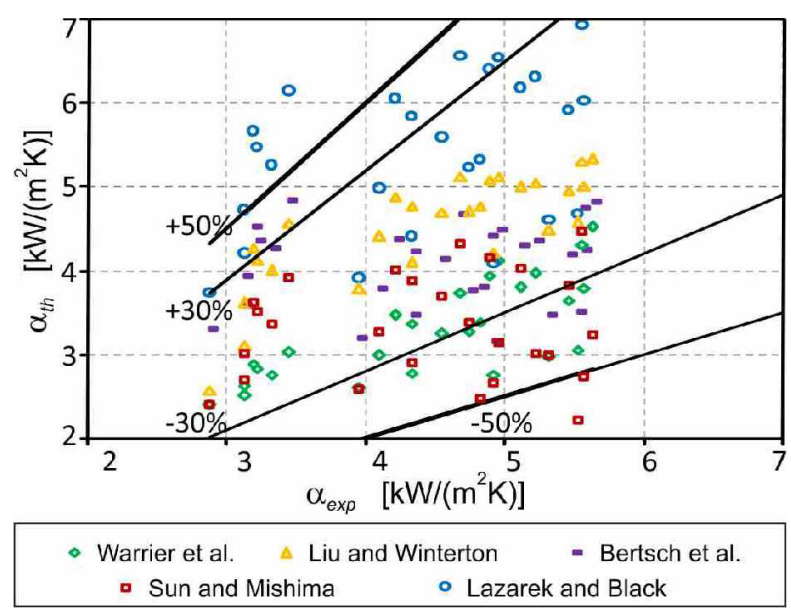

Fig. 4. Comparison of the experimental heat transfer coefficient with theoretically determined values according to selected correlations from literature.

\section{Conclusions}

The results for flow boiling heat transfer in an asymmetrically heated vertical minichannel were presented. The proposed mathematical model described well the heat transfer phenomenon in flow boiling in a vertical minichannel. The Trefftz method applied effectively computes two-dimensional temperature distributions in flow boiling in minichannels. The heat transfer coefficients determined based on the experimental data are consistent with the correlations known from the literature. The best agreement was achieved by using the Liu and Winterton correlation within the margin of error of $\pm 50 \%$. Good compliance was also found when the Bertsch et al. correlation was used.

\section{Acknowledgments}

The research reported herein was partly supported by a grant from the Polish National Science Centre (No. DEC2013/09/B/ST8/02825).

\section{References}

1. M. Piasecka, Int. J. Refrig. 56, 198-212 (2015)

2. M. Piasecka, K. Strąk, B. Maciejewska, Heat Transf. Eng. 38, DOI: 10.1080/01457632.2016. 1189272 (2017)

3. M. Piasecka, B. Maciejewska, Exp. Therm. Fluid Sci. 68, 459-467 (2015)

4. M. Piasecka, Int. J. Heat Mass Transf. 81, 114-121 (2015)

5. B. Maciejewska, K. Strąk, M. Piasecka, Procedia Eng. 157, 82-88 (2016)

6. R. Pastuszko, M. Piasecka, J. Physics Conf. Ser. 395, paper No. 012137 (2012)

7. S. Hożejowska, M. Grabowski, EPJ Web of Conf. 114, 02041 (2016)

8. P.L. Spedding, D.R. Spence, Int. J. Eng. Fluid Mech. 2, 109-118 (1989)

9. S. Hożejowska, R. Kaniowski, M.E. Poniewski, Exp. Therm. Fluid Sci. 78, 18-29 (2016)

10. E. Trefftz, Proc. 2nd Int. Con. App. Mech. 131-137 (1926)

11. S. Hożejowska, R. Kaniowski, M.E. Poniewski, Int. J. Numer. Methods Heat \& Fluid Flow 24, 811-824 (2014)

12. G.M. Lazarek, S.H. Black, Int. J. Heat Mass Transf. 25, 945-960 (1982)

13. Z. Liu, R.H.S. Winterton, Int. J. Heat Mass Transf. 34 2759-2766 (1991)

14. G.R. Warrier, V.K. Dhir, L.A. Momoda, Exp. Therm. Fluid Sc. 26, 53-64 (2002)

15. L. Sun, K. Mishima, Int. J. Heat Mass Transf. 52, 5323-5329 (2009)

16. S.S. Bertsch, E.A Groll, S.A. Garimella, Int. J. Heat Mass Transf. 51, 4775-4787 (2009)

17. M.G. Cooper, Adv. Heat Transf. 16, 157-239 (1984) 